\title{
Evaluation of the Dynamic Characteristics of AZ91D Crankcase Covers and Boxes
}

\author{
L. Zhang, ${ }^{\text {a,1 }}$ H. C. Shang, ${ }^{a}$ Z. Q. Zhao, ${ }^{a}$ and D. F. Zhang ${ }^{\mathrm{b}}$ \\ a College of Mechanical Engineering, Chongqing University, Chongqing, China \\ b National Engineering Research Center for Magnesium Alloys, Chongqing University, Chongqing, \\ China \\ ${ }^{1}$ zhangli20@cqu.edu.cn
}

\begin{abstract}
Dynamic tests are performed on similarly structured crankcase covers and boxes made of AZ91D magnesium and A380 aluminum alloys. The real vibration and noise control effect of an AZ91D magnesium alloy is evaluated, based on the behavior of the integral frequency response function, which is derived from the measured surface vibrations of the crankcase cover under operating conditions. The results indicate that crankcase covers and boxes made of AZ91D magnesium and A380 aluminum alloys with the same geometry possess similar normal characteristics. Both materials are interchangeable. However, the stiffness of AZ91D crankcase covers and boxes is poor. It is also difficult to obtain good engineering vibration and noise effects in the real structure due to an AZ91D high damping capacity. At the same excitation and frequency response at different structure characteristics, the measurement analysis of time-domain response indicates that methods to strengthen the crankcase box stiffness, such as embedding a main bearing steel sleeve, is favorable for improving the dynamic characteristics of an AZ91D crankcase box.
\end{abstract}

Keywords: magnesium alloy, damping capacity, experimental modal analysis, crankcase box, crankcase cover.

Introduction. Magnesium alloy is the lightest material among all engineering ones, which strength and stiffness are similr to those of aluminum alloy and steel [1-4]. Due to its particularly high damping ability, it has a great potential in restraining vibrations and weakening the spread of wave, in order to control noise and stabilize a structure [5-8]. It is widely used in automobile, aviation and other engineering industries [9-11]. This material application is lucrative for manufacturing such automobile components, as crankcase box and crankcase cover. The dynamic performance of specimens made of AZ91D and A380 magnesium alloys is studied in this paper via the modal test analysis performed on specimens made of the above materials with the same geometric structure. Using this method, we can also evaluate the real engineering vibration and noise effect for the magnesium alloys. The engineering NVH effect of AZ91D is evaluated based on the behavior of integrated frequency response function (FRF) and measurements of crankcase cover surface vibration under the engine operation conditions. To analyze the effect of a main bearing seat-embedded steel sleeve on improvement of the dynamic characteristics of AZ91D crankcase box, we used measurements of time-domain response under the same excitation conditions and measurements of frequency response at different structure characteristic positions.

Modal Test and Modal Parameter Identification. Structural dynamic characteristic testing focuses on the study of the structural response to its dynamic load. This testing determines the relationship between the parameters during the dynamic loading. The test of the structure dynamic characteristics allows one to determine the modal parameters, which represent the structure dynamic characteristics, such as inherent frequency, vibration shape (modal vibration type), and modal damping ratio. These values are determined based on the modal test and modal parameter identification, using measured excitation and response data. 
By applying the exciting test method, the $p$ th degree of freedom of $n$ degrees of freedom ratio damping system is obtained and the response of the $r$ th degree of freedom allows one to get the frequency response function $H_{r p}(\omega)$. After $r$ and $p$ attain the values of $1,2, \ldots, n$, the $n \times n$ frequency response functions and forms $n \times n$ ranks of the frequency response function matrix are derived $[12,13]$. The relationship between the frequency response function and modal parameter is as follows:

$$
H_{r p}(\omega)=\sum_{s=1}^{n} \frac{u_{r}^{(s)} u_{p}^{(s)}}{K_{s}-\omega^{2} M_{s}+i C_{s} \omega} .
$$

Here $r, p=1,2, \ldots, n, u_{r}^{(s)}$ and $u_{p}^{(s)}$ are the elements of $r$ th and $p$ th rows of $s$ th rank main modal vector, which are referred to as main vibration type vectors of $r$ and $p$ points, while $K_{s}, M_{s}$, and $C_{s}$ are the modal stiffness, modal mass, and modal damping, respectively.

The modal test yields the modal parameters, when the structure frequency response function is measured. For the modal test of AZ91D and A380 specimens, the modal impact module of LMS Company Virtual.Lab software system was used, which provides the signal processing and data acquisition module for input and processing of signals. The exciting hammer (type 356A15) was integrated with piezoelectricity sensors $(2.03 \mathrm{mV} / \mathrm{g}$ sensitivity) from the PCB company. The exciting force hammer (type $2100 \mathrm{E} 11$ from the PCB company) was used as the modal vibration excitation equipment, while the acceleration transducer $(083 \mathrm{C} 03)$ with sensitivity $2.03 \mathrm{mV} / \mathrm{g}$ from the PCB company acted as the vibration sensor.

Figure 1 shows the modal test analysis system and test components. The test specimens are made of AZ91D and A380 materials, which are used for manufacturing of crankcase boxes and crankcase covers.

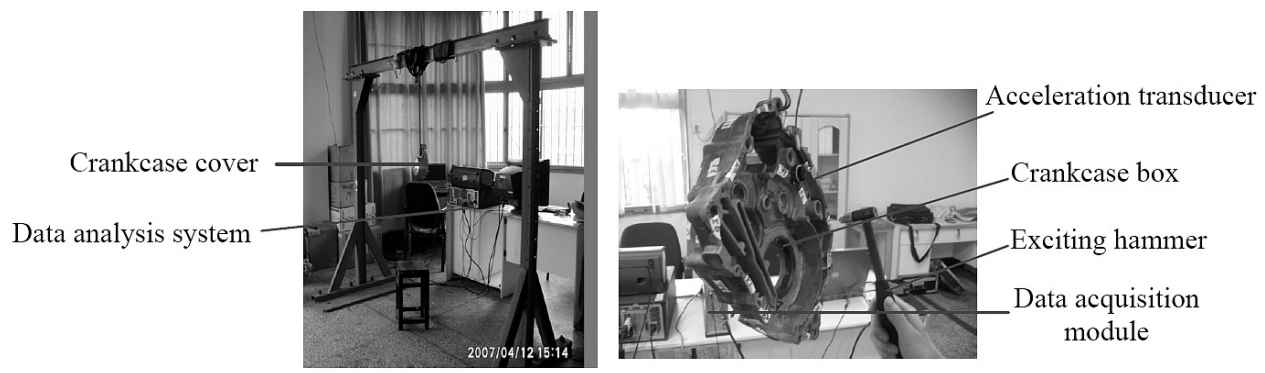

Fig. 1. Modal test analysis system and test components.

To reduce the additional mass of test specimens imposed by sensors and their accessories, the vibration signal point pick-up and point-to-point knocking methods were used in the modal test. There are 38 test points on the crankcase box and 54 on the crankcase cover to represent the structure of the specimens. The frequency bandwidth is set to $4000 \mathrm{~Hz}$ with a sensitivity of $1 \mathrm{~Hz}$. Figure 2 shows the frequency response function and coherence function of the 12th point during testing.

The multiple input least-squares complex frequency-domain method (the LSCF method \& PolyMax method) is used for the modal parameter identification. This method is suitable for the parameter identification for both weak and strong damp-intensive modal systems based on the frequency response function measurements. Even under high damp intensive modal conditions, a steady stabilization diagram can be obtained, which controls the physical modal rank. Even if the modal test is not fully excited, its parameters can be identified. 

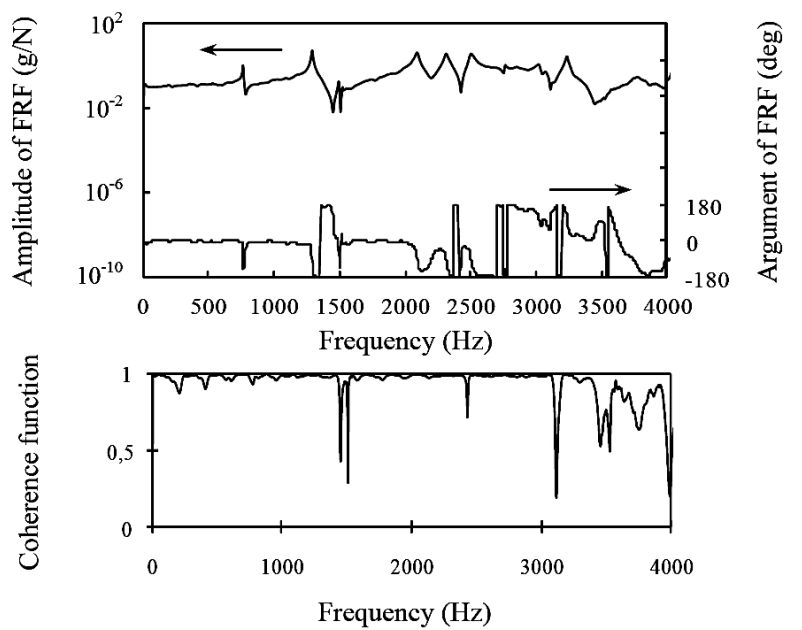

Fig. 2. The frequency response function and coherence function of the AZ91D crankcase box at the 12 th test point.
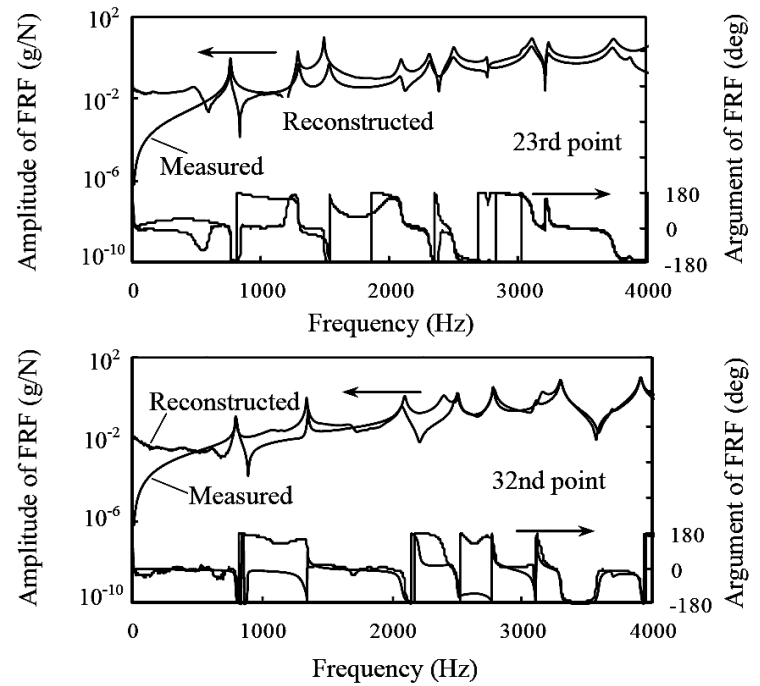

Fig. 3. Evaluation of the AZ91D crankcase box frequency response function via the integrated modal model.

After the modal parameters are identified, the modal parameter identification quality can be evaluated by applying the frequency response function integration and modal assurance criterion (MAC). In Fig. 3, the 23rd and 32nd test points validate the frequency response function of the integrated modal model. The frequency response function is reconstructed based on the identified modal model integration. It shows the consistency with measured frequency response function and the measurement accuracy.

Modal Parameters and Frequency Response Function Characteristics. The plot for specimens simulating the crankcase box and crankcase cover was obtained using the frequency response function integration at all test points. This plot identifies the inherent frequency, vibration type, damp ratio and other parameters of the specimens. As shown in Tables 1 and 2, the crankcase boxes and covers have the 11th modal rank within the set bandwidth. Figure 4 shows the front 4-rank inherent vibration type acquired through the AZ91D crankcase box modal test and the finite element method. Figure 5 depicts the integrated frequency response functions of crankcase cover specimens made of AZ91D and 
$\mathrm{T}$ a b 1 e 1

Modal Parameters of AZ91D and A380 Crankcase Covers

\begin{tabular}{|c|c|c|c|c|c||}
\hline \multirow{2}{*}{$\begin{array}{c}\text { Order } \\
(n)\end{array}$} & \multicolumn{2}{|c|}{ AZ91D } & \multicolumn{2}{|c|}{ A380 } & \multirow{2}{*}{$\begin{array}{c}\text { Ratio } \\
\text { of natural } \\
\text { frequency }\end{array}$} \\
\cline { 2 - 5 } & $\begin{array}{c}\text { Natural } \\
\text { frequency } f, \mathrm{~Hz}\end{array}$ & $\begin{array}{c}\text { Damping } \\
\text { ratio }(\%)\end{array}$ & $\begin{array}{c}\text { Natural } \\
\text { frequency } f, \mathrm{~Hz}\end{array}$ & $\begin{array}{c}\text { Damping } \\
\text { ratio }(\%)\end{array}$ & 0.936 \\
\hline 1 & 524 & 0.60 & 560 & 0.28 & 0.860 \\
\hline 2 & 592 & 1.52 & 688 & 0.46 & 0.936 \\
\hline 3 & 1110 & 1.39 & 1186 & 0.66 & 0.958 \\
\hline 4 & 1727 & 0.95 & 1802 & 0.28 & 0.953 \\
\hline 5 & 2132 & 0.84 & 2238 & 0.30 & 0.935 \\
\hline 6 & 2535 & 1.15 & 2712 & 0.26 & 0.995 \\
\hline 7 & 2843 & 0.56 & 2857 & 0.38 & 1.042 \\
\hline 8 & 3097 & 0.33 & 2973 & 0.18 & 1.037 \\
\hline 9 & 3250 & 0.39 & 3135 & 0.11 & 1.006 \\
\hline 10 & 3638 & 0.34 & 3618 & 0.25 & 0.990 \\
\hline 11 & 3814 & 0.61 & 3851 & 0.21 & \\
\hline \hline
\end{tabular}

T a b 1 e 2

Modal Parameters of AZ91D and A380 Crankcase Boxes

\begin{tabular}{|c|c|c|c|c|c||}
\hline \multirow{2}{*}{$\begin{array}{c}\text { Order } \\
(n)\end{array}$} & \multicolumn{2}{|c|}{ AZ91D } & \multicolumn{2}{c||}{ A380 } & \multirow{2}{*}{$\begin{array}{c}\text { Ratio } \\
\text { of natural } \\
\text { frequency }\end{array}$} \\
\cline { 2 - 6 } & $\begin{array}{c}\text { Natural } \\
\text { frequency } f, \mathrm{~Hz}\end{array}$ & $\begin{array}{c}\text { Damping } \\
\text { ratio }(\%)\end{array}$ & $\begin{array}{c}\text { Natural } \\
\text { frequency } f, \mathrm{~Hz}\end{array}$ & $\begin{array}{c}\text { Damping } \\
\text { ratio } \%)\end{array}$ & 0.955 \\
\hline 1 & 762 & 0.20 & 798 & 0.56 & 0.959 \\
\hline 2 & 1294 & 0.35 & 1350 & 0.74 & 0.947 \\
\hline 3 & 1530 & 0.45 & 1615 & 0.43 & 1.005 \\
\hline 4 & 2088 & 0.77 & 2077 & 0.29 & 0.934 \\
\hline 5 & 2316 & 0.49 & 2479 & 0.19 & 0.999 \\
\hline 6 & 2498 & 0.75 & 2501 & 0.17 & 0.998 \\
\hline 7 & 2771 & 0.17 & 2777 & 0.34 & 1.000 \\
\hline 8 & 3110 & 0.68 & 3111 & 0.24 & 0.981 \\
\hline 9 & 3236 & 0.34 & 3300 & 0.30 & 1.012 \\
\hline 10 & 3741 & 0.65 & 3696 & 0.20 & 0.990 \\
\hline 11 & 3879 & 0.40 & 3917 & & 0.959 \\
\hline
\end{tabular}

A380. Figure 6 illustrates the integrated frequency response functions of crankcase box specimens made of AZ91D and A380.

Tables 1 and 2 demonstrate that the inherent frequency and vibration type of each rank are similar due to the modal parameters identified through testing. The same rank-inherent frequency ratio is close to 1 , and the inherent frequency of specimens made of AZ91D is by about 4\% less than that of A380.

For a linear vibration system with $n$ degrees of freedom, the inherent frequency and inherent vibration type of the system from the non-damp freedom vibration equation can be determined. Its system frequency equation is

$$
\left|[K]-\omega^{2}[M]\right|=0,
$$


Modal test
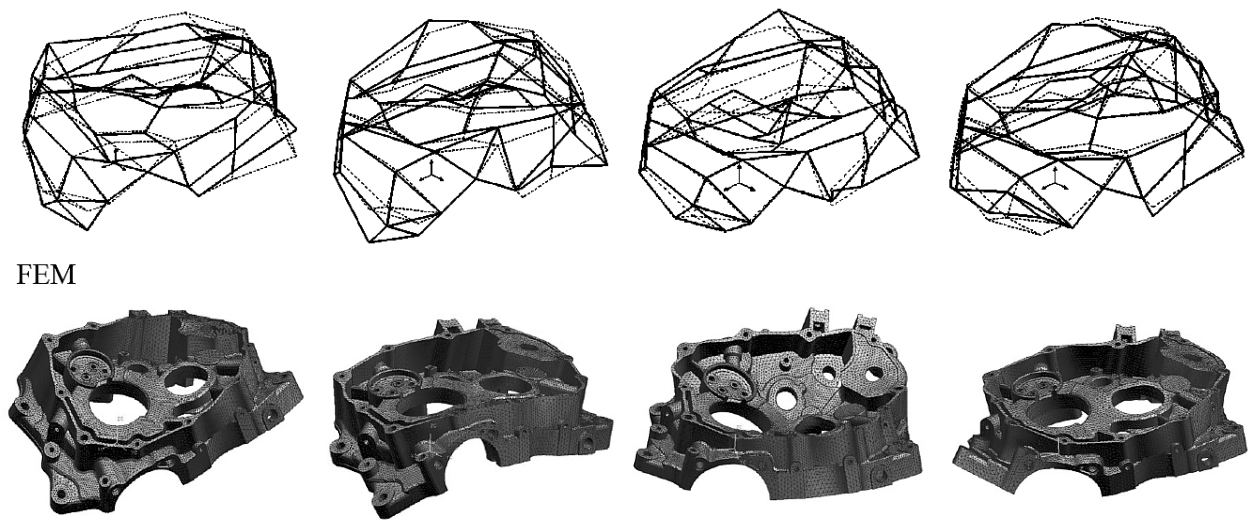

a

b

c

d

Fig. 4. Front 4 rank inherent vibration type of crankcase box made of AZ91D: (a) 1st mode; (b) 2nd mode; (c) 3rd mode; (d) 4th mode.

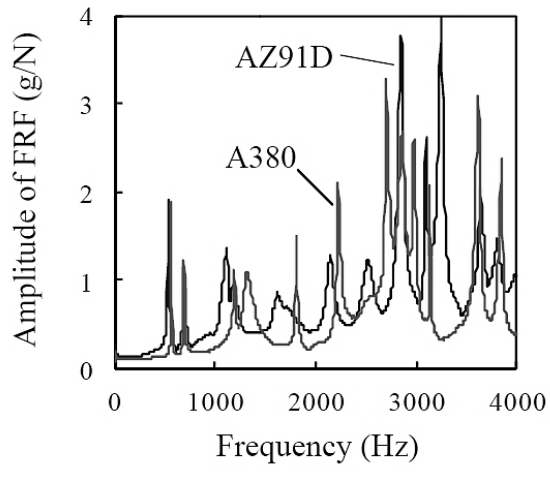

Fig. 5

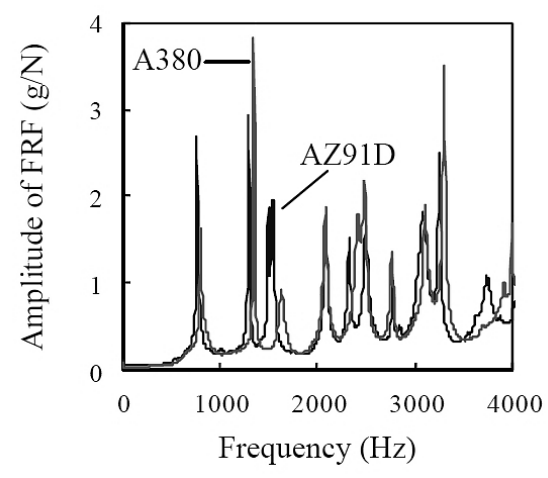

Fig. 6

Fig. 5. The integrated frequency response function of AZ91D and A380 crankcase cover specimens.

Fig. 6. The integrated frequency response function of AZ91D and A380 crankcase box specimens.

where $[M]$ is the mass matrix, $[K]$ is the stiffness matrix, and $\omega$ is the inherent frequency. When the structure is consistent, the formula for specimens composed of AZ91D and A380 can be reduced to the following form:

$$
\begin{gathered}
\frac{[M]_{a z}}{\rho_{a z}}=\frac{[M]_{a}}{\rho_{a}}, \\
\frac{[K]_{a z}}{E_{a z}}=\frac{[K]_{a}}{E_{a}} .
\end{gathered}
$$

Here, $\rho_{a z}$ and $\rho_{a}$ represent the material density of AZ91D and A380, respectively, $E_{a z}$ and $E_{a}$ are the elastic moduli of AZ91D and A380, respectively. From the above equation we can conclude that the same rank-inherent frequency ratio of the two materials is:

$$
\frac{\omega_{a z, s}}{\omega_{a, s}}=\left(\frac{E_{a z}}{\rho_{a z}}\right)^{1 / 2}\left(\frac{E_{a}}{\rho_{a}}\right)^{1 / 2}, \quad s=1,2, \ldots, n,
$$


where $\omega_{a z, s}$ and $\omega_{a, s}$ are the sth inherent frequencies of AZ91D and A380 specimens, respectively. Therefore, for the same structure, the same rank-inherent frequency ratios of AZ91D and A380 specimens are controlled only by the material properties of the vibration system.

The ratios between the elastic modulus and density of AZ91D and A380 are similar. Because of this similarity, using Eq. (5), one can be conclude that for the same structure the ratio of the same rank-inherent frequency ratio is close to 1 . The density modulus of AZ91D is $45 \mathrm{GPa}$ and its elastic modulus is $1810 \mathrm{~kg} / \mathrm{m}^{3}$. For A380 these vaklues are: 71.59 $\mathrm{GPa}$ and $2740 \mathrm{~kg} / \mathrm{m}^{3}$, respectively. The basic properties of the two materials imply the approaches of inherent frequency and inherent vibration type.

Tables 1 and 2 show that the modal damp ratio of AZ91D specimens is less than that of A380 only under certain conditions. Figures 5 and 6 show that crankcase box specimens made of AZ91D and A380 have very similar integrated frequency response functions. Moreover, the integrated frequency response function of crankcase cover specimens made of AZ91D is slightly higher than that of A380.

Evaluation of Vibration and Noise Effect on AZ91D. The frequency response function is the relationship between frequency domain input and output. The integrated frequency response function of a structural system incorporates all test points and implies the linear combination of the frequency response function. Using the total information on the specimen integrated frequency response function, one can determine the dynamic characteristics of the structural system. Therefore, it can be used as an evaluation reference for the NVH effect.

Figure 6 shows that for AZ91D and A380 crankcase box and cover specimens with the same structure, when the AZ91D frequency response function curve is located higher than that of A380, the same excitation causes AZ91D to have higher surface vibration and noise energy than those in A380 specimens. Figure 7 shows the measured values of the vibration acceleration in AZ91D and A380 surfaces under engine operation conditions. The AZ91D surface vibration amplitude is somewhat higher than that of A380. Due to this, the high damping characteristics of AZ91D in the structural system vibration and noise control application are hard to demonstrate.
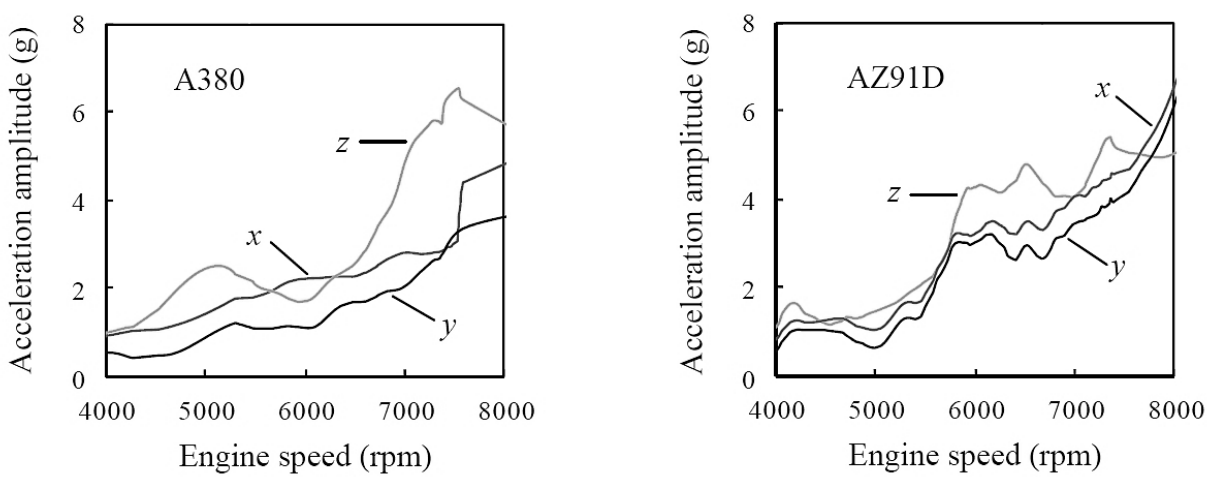

Fig. 7. Frequency response functions of AZ91D and A380 crankcase box and cover specimens.

To analyze the effect of AZ91D high-damping characteristics on the dynamic response characteristics with the same excitation pulse input, the comparison tests of time domain excitation response characteristics were performed using the specimens made of AZ91D and A380. Figures 8 and 9 show the time domain response curves of crankcase box and cover specimens made of AZ91D and A380 at the same test point. These graphs show that AZ91D specimens have a better vibration amplitude attenuation response excitation signal than A380 ones, while high damping characteristics are exhibited by AZ91D. 


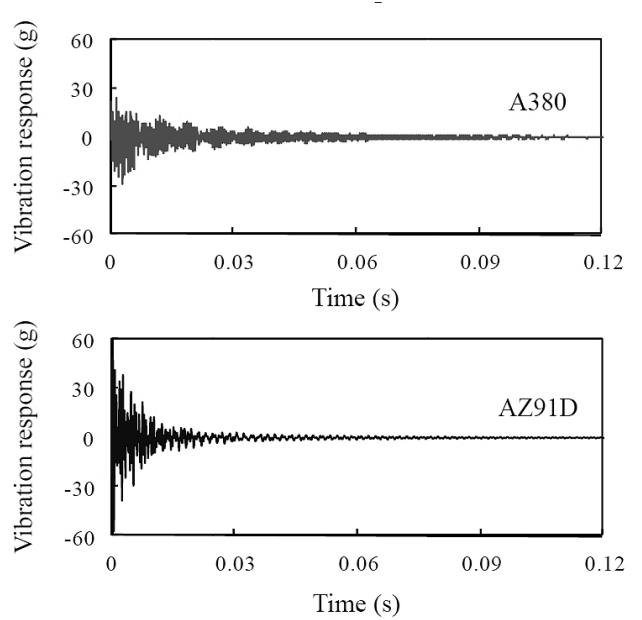

Fig. 8
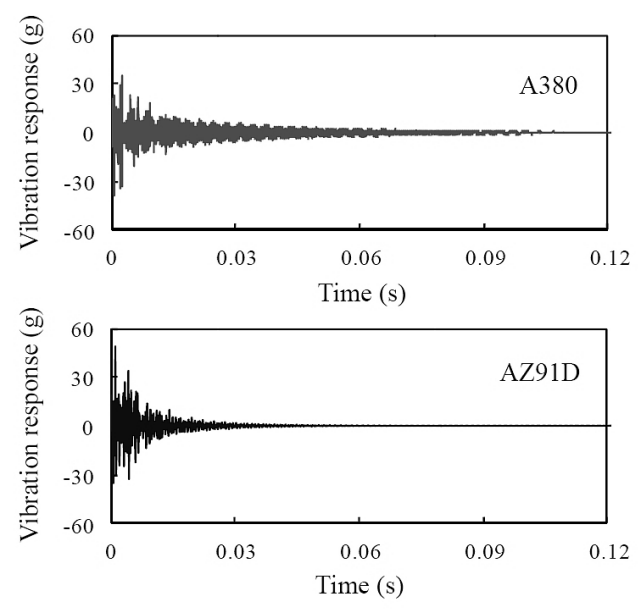

Fig. 9

Fig. 8. Time domain excitation response of AZ91D and A380 crankcase box specimens.

Fig. 9. Time domain excitation response of AZ91D and A380 crankcase cover specimens.

However, at the initial phase with the same excitation force, the time domain response amplitude of AZ91D is higher than that of A380. This is more prounced in crankcase boxes and cover specimens with a lower-stiffness structure.

By exciting specimens at the $p$ th degree of freedom and testing the response at the $r$ th degree of freedom, based on Eq. (1), the frequency response function equation can be reduced to:

$$
H_{r p}(\omega)=\sum_{s=1}^{n} \frac{1}{K_{e s}\left[\left(1-\bar{\omega}_{s}^{2}\right)+2 i \xi_{s} \bar{\omega}_{s}\right]},
$$

where $\omega_{s}$ is the frequency ratio of the $s$ th rank modal, $\xi_{s}$ is the damping ratio of the $s$ th rank modal, and $K_{e s}$ is the equivalent stiffness of the $s$ th rank modal which is related to the position of response point $r$ and excitation point $p$ and represents the structural equivalent stiffness in-between the two points.

It can be concluded that, in case when specimens made of two materials possess similar inherent characteristics, the frequency response function is related not only to the modal damping ratio $\xi_{s}$, which represents damping characteristics, but also to the modal equivalent stiffness, which represents the structural stiffness.

For specimens of the same structure made of these two materials, the equivalent stiffness between the response test point and the exciting point is mainly controlled by the elastic modulus of each material. Because the AZ91D elastic modulus is less than that of A380, the stiffness of specimens made of AZ91D is less than that of A380 using the same structure. The lower structure stiffness of AZ91D causes a higher response amplitude for the external excitation, which compensates the material better damping and makes it difficult to exhibit the high damp characteristics of AZ91D in real structural applications. Because of this, it is crucial to apply corresponding methods to improve the structural stiffness after replacing A380 with AZ91D.

In Fig. 10, the 17th, 22nd, and 5th test points are used as excitation points to measure the frequency response characteristics. The distances between each test point and acceleration sensor are similar. Also, between the 17 th test point and the response point there is an embedded steel sleeve structure. There is no structural characteristic that changes the intensity and stiffness between the 22nd and 5th test points and the response point. The 


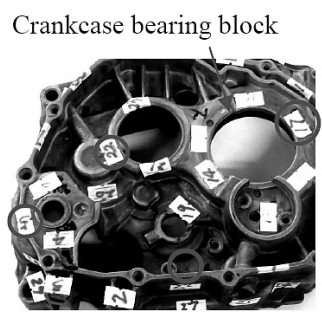

Front view

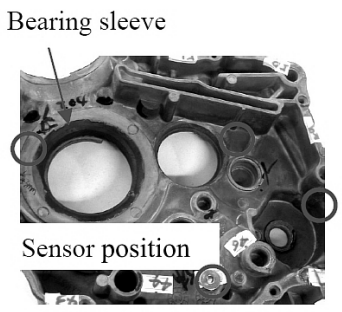

Back view

Fig. 10. The 17th, 22nd, and 5th test point of crankcase box made of AZ91D.
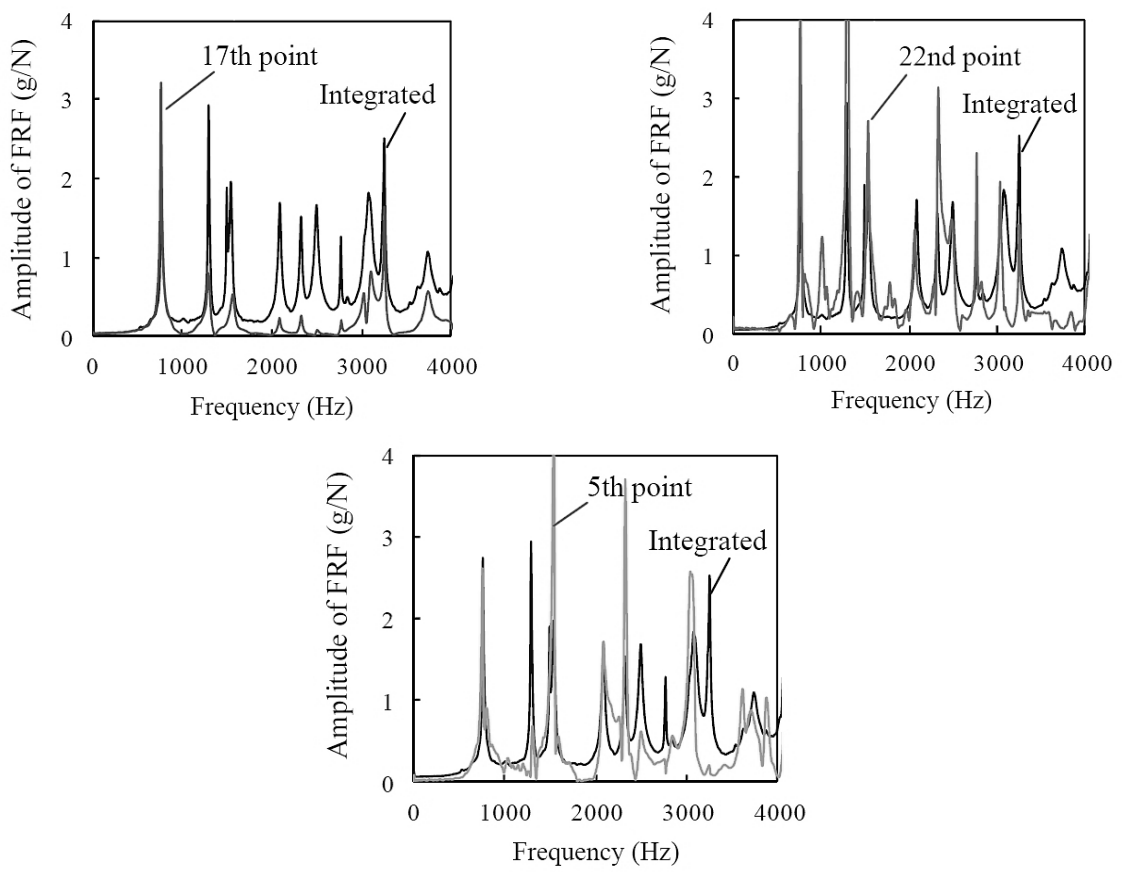

Fig. 11. The frequency response function of structure characteristics position of crankcase box made of AZ91D.

comparison of the frequency response function of each point and the integrated frequency response function of crankcase box specimens (curve of AZ91D in Fig. 6) are shown in Fig. 11. It can be seen that the frequency response function of the 17th test point is much less than the integrated frequency response function of the AZ91D crankcase box specimen, while those of the $22 \mathrm{nd}$ and 5 th test points are similar. The difference among the 17 th, 22nd, and 5th test points proves that the structural stiffness has a significant effect on the integrated frequency response function of a crankcase box. In addition to the damp characteristics of the material, the structural stiffness is an important factor controlling the structureal NVH effect. This is an effective method to improve the dynamic characteristics of an AZ91D crankcase box, which allows one to improve the structural stiffness by reasonably embedding steel sleeves in the local areas.

Conclusions. AZ91D and A380 crankcase box and crankcase cover specimens with the same structure have similar inherent frequency and vibration modules. This is primarily due to the fact that basic characteristic parameters of the two materials are very similar, as to the ratio between elastic modulus and density. The comparability of inherent characteristic parameters makes it convenient to replace the A380 aluminum alloy with AZ91D magnesium alloy in many engineering applications. 
Although the modal damping ratio of AZ91D crankcase boxes and covers is higher than that of A380, its high damping characteristics are hard-to-attain. The surface vibration amplitude of the crankcase cover made of AZ91D is higher than that of A380, as seen from the measurement of crankcase cover surface vibration amplitude under an engine operation conditions.

This indicates that the crankcase box and crankcase cover specimens made of AZ91D have better attenuation effect on the vibration amplitude than A380 specimens. This is confirmed by measurement of time-domain response using the same excitation conditions. Because of the lower structural stiffness of AZ91D, the response amplitude of the specimens to the external excitation is increased and counteracts the benefits of high damping characteristics of AZ91D. This makes it difficult to exhibit the damping characteristics of AZ91D in real structures.

When using AZ91D to replace A380 in a structure, it is expidient to increase the structural stiffness using the respective methods. Test results and calculated frequency response characteristics of the structure characteristics positions confirm that one can improve the dynamic characteristics of AZ91D crankcase boxes by applying the embedded main bearing seat steel sleeves.

Acknowledgments. The authors would like to thank the 973 National Grand Theoretical Research Program (2007CB613700), and the National Outstanding Youth Scientific Fund (50725413) for financial support.

1. O. A. Lambri, W. Riehemann, and Z. Trojanova, "Mechanical spectroscopy of commercial AZ91 magnesium alloy," Scripta Mater., 45, 1365-1371 (2001).

2. G. Song, "Recent progress in corrosion and protection of magnesium alloys," $A d v$. Eng. Mater., 7, 563-586 (2005).

3. J. C. Benedyk, "Magnesium advances in automotive applications," Light Metal Age, 63, 36-38 (2005).

4. B. P. Powell, "Magnesium alloys cast into auto powertrain components," Adv. Mater. Process., 162, 60-61 (2004).

5. N. Jeal, "High-performance magnesium," Adv. Mater. Process., 163, 163-167 (2005).

6. J. Zhang, Y. L. Tao, Z. F. Sun, et al., "Vibration damping capacity of AZ91D magnesium alloys," Chinese J. Mech. Eng., 42, 186-189 (2006).

7. X. N. Zhang, "Effect of reinforcements on damping capacity of pure magnesium," $J$. Mater. Sci. Lett., 22, 503-505 (2003).

8. D. Wan, J. Wang, L. Lin, Z. Feng, and G. Yan, "Damping properties of $\mathrm{Mg}-\mathrm{Ca}$ binary alloys," Physica B: Condensed Matter, 403, 2438-2442 (2008).

9. N. Nishiyama and S. Asano, "Evaluation of amplitude dependence of internal friction in high-damping metals," J. Japan Inst. Metals, 65, 109-114 (2001).

10. J. Goken and W. Riehemann, "Damping behavior of AZ91 magnesium alloy with cracks," Mater. Sci. Eng. A, 370, 417-421 (2004).

11. S. G. Pantelakis, N. D. Alexopoulos, and A. N. Chamos, "Mechanical performance evaluation of cast magnesium alloys for automotive and aeronautical applications," $J$. Eng. Mater. Technol., 129, 422-430 (2007).

12. J. Y. Yang, Test Modal Analysis, Beijing Institute of Technology Press, Beijing (1990).

13. H. M. Shi, G. Chen, and Y. Wu, Mechanical Vibration System - Analysis, Measurement, Modeling, Control, Huazhong University of Science and Technology Publishing House, Wuhan (1992). 